\title{
İşitme cihazı kullanıcısı bebeklerin görsel pekiştirmeli konuşmayı ayırt etme yöntemi ile değerlendirilmesi: Olgu serisi
}

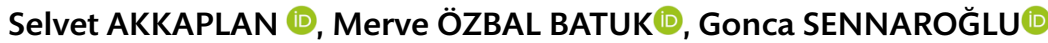 \\ Hacettepe Üniversitesi Sağlık Bilimleri Fakültesi, Odyoloji Bölümü, Ankara, Türkiye
}

öz

\begin{abstract}
Konuşma algısı ölçümleri odyoloji test bataryasının önemli bir parçasıdır. Erken dönemde işitme kaybının araştırılması ve uygun amplifikasyon için işitsel yolun konuşma algısı açısından değerlendirilmesi önemlidir. Bebeklerde dil gelişimi seviyesi nedeniyle konuşma algılama becerilerini yetişkinlerde kullanılan konuşma test bataryası ile objektif şekilde değerlendirmek mümkün değildir. Bebeklerde konuşma algısı ölçümü için objektif sonuçlar veren test bataryası kullanılması gereklidir. Bebeklerde konuşmayı ayırt etme becerisini değerlendirmede en sık kullanılan test tekniği Visual Reinforcement Infant Speech Discrimination (VRISD) yöntemidir. $\mathrm{Bu}$ çalışmanın amacı, işitme cihazı kullanıcısı olan 6-18 aylık 3 bebeğin konuşmayı ayırt etme becerilerinin VRISD test yöntemi ile değerlendirilmesidir. Bu çalışmada kullanılan VRISD test protokolünde, /a/ ile /i/ ve / ba/ ile /da/ konuşma uyaranları eşleştirilerek test uyaranları oluşturulmuştur. Bu uyaran çiftleri biri hedef ses, diğeri arka plan ses olacak şekilde sıralanmış olup tekrarlı ses dizini oluşturularak hoparlör aracılığı ile $70 \mathrm{~dB}$ 'de sunulmuştur. Görsel pekiştireç olarak ise bebeğin ilgisini çeken animasyonlu video kullanılmıştır. Bilateral işitme cihazı kullanıcısı 3 bebeğin konuşmayı ayırt etme becerileri VRISD testi ile değerlendirilmiş olup olgulara ait sonuçlar sunulmuştur. Çalışmanın sonucunda işitme cihazı kullanıcısı bebeklerin konuşmayı ayırt etme becerileri VRISD test yöntemi ile değerlendirilecektir; bu sonuçlar habilitasyon ve amplifikasyon programlamasına katkı sağlamaktadır.
\end{abstract}

Anahtar Sözcükler: İşitme cihazı, konuşma algısı, pediatrik odyoloji
ABSTRACT

\section{Evaluation of babies with hearing aids using visual reinforced infant speech discrimination method: A case series}

Speech perception measurements are an important part of the audiology test battery. It is important to investigate hearing loss in the early period and to evaluate the auditory pathway in terms of speech perception for appropriate amplification. Due to the level of language development in infants, it is not possible to objectively evaluate speech perception skills with the speech test battery used in adults. It is necessary to use a test battery that gives objective results for the measurement of speech perception in infants. Visual Reinforcement Infant Speech Discrimination (VRISD) method is the most commonly used test technique to evaluate speech discrimination skills in infants. The aim of this study is to evaluate the speech discrimination skills of 3 babies aged 6-18 months, who are hearing aid users, with the VRISD test method. In the VRISD test protocol used in this study, test stimuli were created by matching /a/ with /i/ and /ba/ with /da/ speech stimuli. These stimulus pairs are arranged as one target sound and the other background sound, and they are presented at $70 \mathrm{~dB}$ via loudspeaker by creating a repeating sound sequence. Animated video that attracts the attention of the baby was used as visual reinforcement. Speech discrimination skills of 3 babies with bilateral hearing aids were evaluated with the VRISD test, and the results of the cases are presented. As a result of the study, speech discrimination skills of babies with hearing aids will be evaluated with the VRISD test method. These results contribute to habilitation and amplification programming.

Keywords: Hearing aid, speech perception, pediatric audiology

Cite this article as: Akkaplan, S., Batuk, M.Ö., Sennaroğlu, G. (2021). İşitme cihazı kullanıcısı bebeklerin görsel pekiştirmeli konuşmayı ayırt etme yöntemi ile değerlendirilmesi: Olgu serisi. TurkJ Audiol Hearing Res, 4(3):86-90.

\section{GíRiş}

İşitme kaybının erken tespiti ile amplifikasyona erişim ve uygun şekilde programlanmış işitme cihazlarıla işitsel deneyim, işitme kaybı olan küçük çocuklar için konuşma dili gelişimine fayda sağlar (Moeller, 2000; Tomblin, Oleson, Ambrose, Walker, \& Moeller, 2014). Evrensel yenidoğan işitme taraması programı sayesinde erken dönemde işitme kaybı tanıs1, uygun amplifikasyon uygulamaları ve eğitim programları yapılabilmektedir (Downs \& Sterritt, 1967). Erken dinleme deneyimleri, konuşma ve dil gelişimi için kritik öneme sahiptir (Sloutsky \& Napolitano, 2003; Zupan \& Sussman, 2009). 
Çocuklar, erken teşhisin ardından etkili müdahale aldıklarında, normal işiten akranlarıyla eşit düzeyde dil geliştirme firsatlarına sahip olurlar (Tomblin et al., 2014).

Literatürde normal işitmeye sahip bebeklerde konuşmayı algılama becerilerini değerlendirme yöntemleri araştırılmış ve normal işiten bebeklerin yaşamın ilk yıllarında fonem ayırt etme becerisindeki gelişim incelenmiştir (Eilers, Gavin, \& Wilson, 1979; Eimas, Siqueland, Jusczyk, \& Vigorito, 1971; Grieser \& Kuhl, 1989; Kuhl, 1991; Lisker \& Abramson, 1964; Nozza, 2000; Nozza \& Wilson, 1984; Janet F Werker \& Tees, 1984). Normal işiten bebeklerin yaşamın ilk yıllarında anadile maruz kalmalarının, konuşma algısı kabiliyetini etkilediği bilinmektedir. Bebeklerin fonemleri nasıl sınıflandırdıklarını inceleyen araştırmalar, ünlü kategorilerinin yaklaşık 6 ay ve öncesine kadar, ünsüz kategorilerde ise 12 ay öncesine kadar olan sürede anadile maruziyet ile şekillendiği belirtilmiştir. Bunun sebebi muhtemelen ünlülerin ünsüzlerden daha belirgin olmalarıdır (Kuhl, 1991; Strange \& Jenkins, 1978; Janet F Werker \& Tees, 1984). Bu bulgular erken anadile maruziyetin, bebeklik döneminde fonolojik becerilerin geliştirilmesinde önemli bir etkisi olduğunu düşündürmektedir. Halen, işitme cihazı kullanıcısı konjenital işitme kaybı olan bebeklerde fonem ayırt etme becerisi hakkında sınırlı bilgi bulunmaktadır.

Günümüzde işitme kaybı bulunan bebeklerin konuşma algısını değerlendiren ebeveyn gözlem raporları yaygın olarak kullanılmaktadır (K. Uhler \& Gifford, 2014). Ancak bu gözlem raporları objektif değerlendirme sağlamaz. Bebeklerde bu yetenekleri değerlendirmek için Bebekler için Görsel Pekiştirmeli Konuşmayı Ayırt Etme (Visual Reinforcement Infant Speech Discrimination / VRISD) yöntemi kullanılmıştır. Laboratuvar ortamında gerçekleştirilen VRISD yöntemi, araştırmacılar tarafından normal işitmeye sahip bebeklerde konuşmayı ayırt etme becerini incelemek için yaklaşık otuz yıldır kullanılmaktadır. VRISD yöndetimde bebeklerin konuşma, müzik, ses ve frekans algılama yetenekleri değerlendirilir. Werker ve ark. tarafından açıklanan prosedürün birkaç güçlü yönü vardır. Bunlardan birincisi, VRISD bir davranışsal işitsel testtir ve bu nedenle fonksiyonel işitme yeteneği hakkında fikir verir. İkincisi, görsel pekiştireç kullanılması bebeğin cevaplarını güçlendirir. Üçüncüsü çoklu test denemeleri sunulabilir. Son olarak, bu prosedürün çeşitli araştırmalarda kullanımına izin veren esnek tasarımlar geliştirilebilir (Janet F. Werker, Polka, \& Pegg, 1997)

Bebeklerin konuşma algısı yeteneklerinin nesnel olarak ölçülebilmesi, konuşma dilinin gelişimi için gerekli işitsel girdiyi sağladığını doğrulamaya yardımcı olabilir. Aynı zamanda bebeklerde konuşma algısı ölçümlerinden elde edilen sonuçlar, habilitasyonun yönlendirilmesinde yardımcı olabilmektedir (K. M. Uhler, Baca, Dudas, \& Fredrickson, 2015).

İşitsel gelişim ve dil gelişiminin, işitsel uyaranlara erken maruz kalmaya bağlı olduğu düşünülmesine rağmen periferik işitme kaybı nedeniyle bebeğin işitsel deneyimden mahrum kaldığında erken dönemdeki gelişiminin ne kadar değiştiği hakkındaki bilgiler sınırlıdır. Bebeklerde konuşma algısını değerlendiren Türkçe test yöntemi geliştirerek, işitme cihazı kullanıcılarında uygulanabilirliğini değerlendirmek bu çalışmanın temel odak noktasıdır. Çalışmamızın amacı; 6-18 ay arasındaki işitme cihazı kullanıcısı 3 bebeğin konuşmayı ayırt etme becerilerinin VRISD yöntemi ile değerlendirmektir.

\section{GEREÇ VE YÖNTEM}

$\mathrm{Bu}$ çalışmaya, cihazı uygulanmış ve odyolojik takipleri yapılan 6-18 ay arasındaki bilateral işitme cihazı kullanan 3 bebek dahil edilmiştir.

Test protokolünde kullanılan /a/, /i/, /ba/ ve /da/ konuşma sesi uyaranları ana dili Türkçe olan kadın konuşmacı tarafindan stüdyo ortamında kayıt altına alınmıştır. Kayıt alınırken Neumann TLM193 marka mikrofon ile Cubase 8.1 yazılımı kullanılmıştır. Preamplifikatör modeli BAE 1073 MP ve dönüştürücü olarak Lynx Hilo olarak seçilmiştir.

/a/ ile /i/ ve /ba/ ile /da/ konuşma uyaranları eşleştirilerek test uyaranları oluşturulmuştur. $\mathrm{Bu}$ uyaran çiftleri biri hedef ses (\%15 oranında) diğeri ise arka plan ses (\%85 oranında) olacak şekilde oddball paradigmasına göre sıralanmış olup tekrarlı ses dizini haline PRAAT programında getirilmiştir. Test aşamasında arka plan ses olarak /a/ uyaranı hedef ses olarak /i/ uyaranı; / ba/ uyaranını arka plan ses ve /da/ uyaranını hedef ses olarak kullanılmıştır. /a/ ve /i/ uyaranlarının her biri 500 msn süreli olarak belirlenmiştir. /ba/ ve /da/ uyaranları ise ünsüz-ünlü şeklinde sırasıyla $100 \mathrm{msn}$ ve $400 \mathrm{msn}$ süreli olarak sıralanmıştır. Uyaranlar arası süre ise 1200 msn olarak belirlenmiştir.

Testler sessiz kabinde, bebeklerin bilateral işitme cihazları takılı ve odanın ortasında mama sandalyesinde veya ebeveynin kucağında iken, orta hatta oynayabileceği oyuncakları kullanacak test asistanı bebeğin tam karşısında oturur pozisyonda yer almıştır. Test uyaranları bebeğin baş hizasından 1 metre uzaklıkta arkasında yer alan hoparlör aracılığı ile $70 \mathrm{~dB}$ HL'de sunulmuştur. Görsel pekiştireç olarak bebeğin ilgisini çeken animasyonlu video kullanılmıştır. Bebeğin her iki tarafına görebileceği hizada bulunan bilgisayar ekranlarından kısa süreli dikkat çekici videolar pekiştireç olarak kullanılmıştır.

Test protokolünde yer aldığı gibi test, deneme aşaması ve test aşaması olmak üzere 2 aşamadan oluşmaktadır. Deneme aşamasında testin öğretilmesi amacıyla her bir uyaran için deneme yapılmıştır. Deneme aşaması sırasında arka plan ses olan /a/ konuşma uyaranı değiştirilmeden sunulurken, test denemelerinde 3 tekrarlı /i/ uyaranı sunulmuştur. Şartlandırma amacıyla /a/ uyaranından her /i/ uyaranına geçişte Video VRA ile pekiştireç sunularak test çocuğa öğretilmiştir. Deneme aşaması tamamlanarak bebeğin testi öğrendiği düşünüldüğünde ise test aşamasına geçilmiştir. Test aşamasında bebek orta hatta 
iken hedef uyaran geldiğinde başını görsel pekiştirece çevirmesi cevap olarak kabul edilmiştir. Arka plan sesin aralarına tahmin edilemeyecek şekilde randomize olarak yerleştirilmiştir. 15 hedef ses /i/ uyaranı içermektedir. Değerlendirme 15 denemede kaç doğru ayırt etme cevabı gözlendiğine bağlı olarak yapılmıştır. (K. M. Uhler et al., 2015).

\section{BULGULAR}

\section{Olgu 1}

15 aylık erkek bebek hasta, 5 aylık iken menenjit hikayesiyle kliniğimize yönlendirildi. Bilateral işitme kaybı tanısını 6 aylıkken alan hasta 7 aylıkken cihazlandırıldı. 39 haftalık normal doğum ile sorunsuz doğan bebeğin hikayesinde belirgin bir risk faktörü gözlenmemektedir. Yapılan objektif ve subjektif odyolojik değerlendirmeler sonucunda bilateral ortaileri derecede sensörinöral tip işitme kaybı tanılanan (Şekil 1) hastaya IT/MAIS ebeveyn gözlem raporu ve DENVER Gelişimsel Tarama Testi uygulandı. IT/MAIS skoru 28 olarak değerlendirilen hastanın DENVER tarama testinde dil gelişimi dışında diğer bütün gelişim alanlarında normal gelişim gösterdiği belirlendi. 8 aydır bilateral işitme cihazı kullanan hasta VRISD yöntemi ile değerlendirildi ve /a/-/i/ uyaranlarında ayırt etme cevab1 7/15 iken; /ba/-/da/ uyaranlarında ayırt etme cevab1 0/15 olarak elde edildi. İlk kullanılan uyaranda teste koopere olan hastanın ikinci uyaranda kooperasyonun bozulduğu gözlendi. Bunun sebebinin bebeğin testten sıkılmış olabileceği düşünüldü. Teste ara verilip tekrar değerlendirilen hastanın skorlarında değişiklik gözlenmedi.

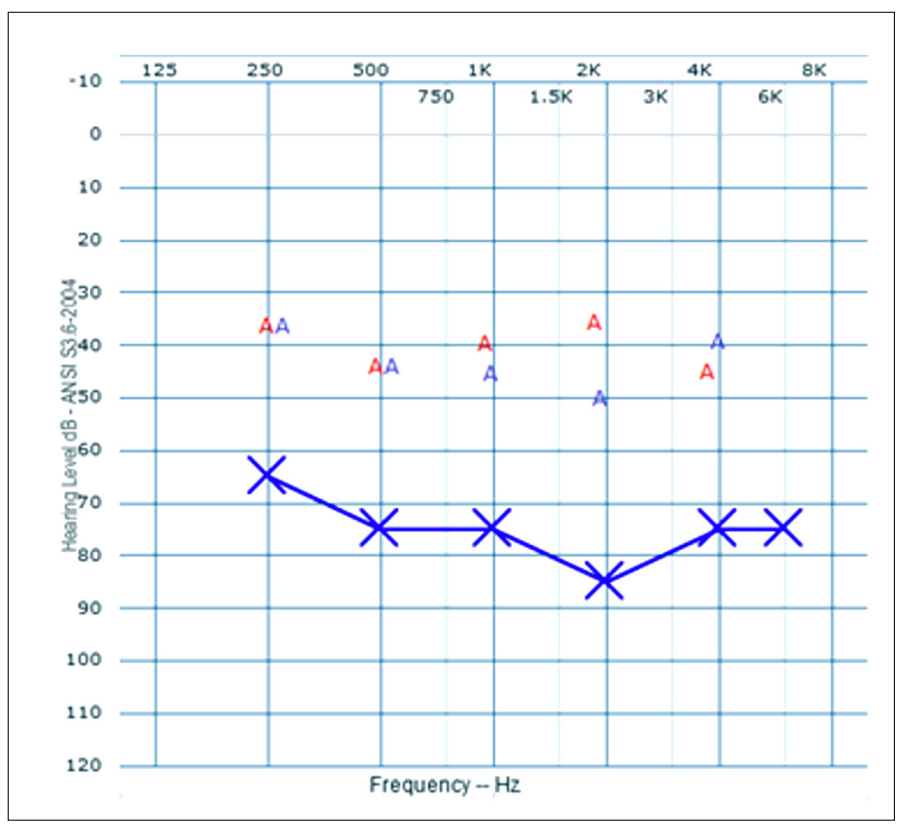

Şekil 1. Olgu 1: 15 aylık iken yapılan davranışsal odyolojik değerlendirme sonuçları

\section{Olgu 2}

Erken doğum hikayesi bulunan (36. Gestasyonel hafta) 11 aylık erkek bebek laringomalazi tanısıyla Nöroloji ve FTR Bölümlerinde takiplidir. 7 aydır bilateral işitme cihazı kullanan hastanın kliniğimize geldiğinde 8 aylık iken yapılan odyolojik değerlendirmeside; insert kulaklıklar ile VRA uygulandı ve eşik üstü davranım gözlendi (Şekil 2). Eşik ABR yapılması planlandı. Kliniğimize geldiğinde 10 aylık iken yapılan objektif odyolojik değerlendirme sonuçları Tablo 1'de gösterilmiştir.

/a/-/i/ uyaranları kullanılarak yapılan VRISD testinde, testi öğrenme aşamasında $3 \mathrm{kez}$ doğru cevap elde edilen hastadan, test aşamasında hiç doğru cevap alınamadı. Rutin odyolojik kontrollerine geldiğinde test tekrarı planlandı.

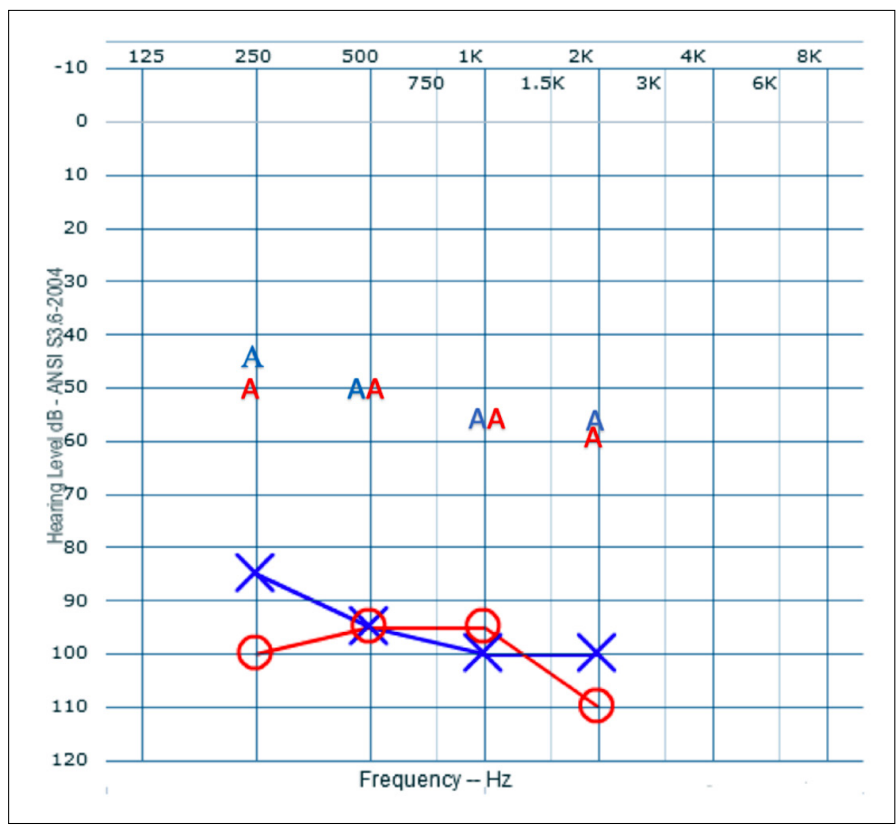

Şekil 2. Olgu 2: 8 aylık iken yapılan davranışsal odyolojik değerlendirme sonuçları

Tablo 1. Olgu 2: Objektif Odyolojik Değerlendirme Sonuçları

\begin{tabular}{|l|c|c|c|c|}
\hline \multicolumn{5}{|c|}{10 aylık iken yapılan odyolojik değerlendirme } \\
\hline 10 aylık ABR & Klik & $500 \mathrm{~Hz}$ & Timpanogram & OAE \\
\hline Sağ Kulak & $50 \mathrm{dBnHL}$ & $70 \mathrm{dBnHL}$ & A & $(-)$ \\
\hline Sol Kulak & $50 \mathrm{dBnHL}$ & $80 \mathrm{dBnHL}$ & A & $(-)$ \\
\hline
\end{tabular}

\section{Olgu 3}

Yenidoğan işitme taramasından kalan 7 aylık kız bebeğin hikayesinde işitme kaybı için herhangi bir risk faktörü bulunmamaktadır. 4 aylıkken işitme kaybı tanılanan ve 6 aylıkken işitme cihazı uygulanan hastaya kliniğimizde insert kulaklıklar VRA testi uygulandı ve tepkileri güvenilirdi. Saf ses uyaranlara eşik üstü yanıt verdiği gözlendi (Şekil 3). 1 aydır işitme cihazı kullanan hasta, VRISD yöntemi ile değerlendirildi ve /a/-/i/, /ba/-/da/ uyaran çiftlerinde doğru yanıt gözlenmedi.

Tablo 2. Olgu 3: Objektif Odyolojik Değerlendirme Sonuçları

\begin{tabular}{|l|c|c|c|}
\hline 6 aylık ABR & Klik & Timpanogram & OAE \\
\hline Sağ Kulak & $60 \mathrm{dBnHL}$ & Düz & $(-)$ \\
\hline Sol Kulak & $50 \mathrm{dBnHL}$ & Düz & $(-)$ \\
\hline
\end{tabular}

Tablo 3. VRISD Test Sonuçları

\begin{tabular}{|l|c|c|c|}
\hline & OLGU 1 & OLGU 2 & OLGU 3 \\
\hline$/ \mathrm{A} /-$ I/ & $7 / 15$ & $0 / 15$ & $0 / 15$ \\
\hline /BA/- /DA/ & $0 / 15$ & $0 / 15$ & $0 / 15$ \\
\hline
\end{tabular}




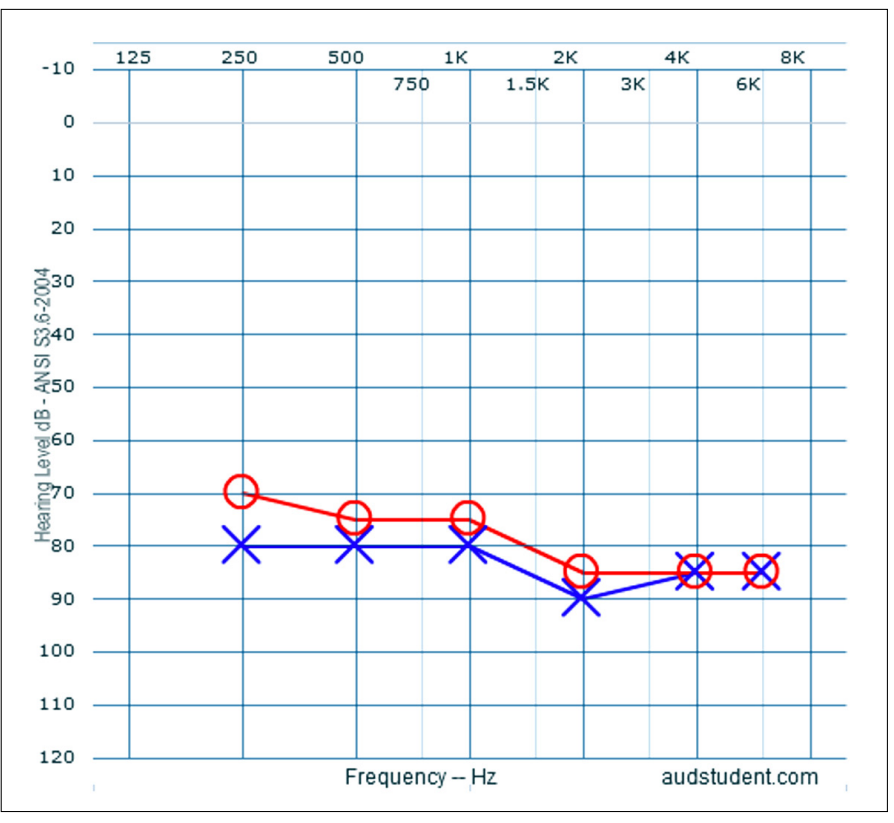

Şekil 3. 7 aylık iken yapılan davranışsal odyolojik değerlendirme sonuçları

\section{TARTIŞMA VE SONUÇ}

$\mathrm{Bu}$ olgu serisi çalışmasında işitme cihazı kullanıcısı bebekler VRISD testi ile konuşmayı ayırt etme becerileri değerlendirilmiştir. Olgu 1'de elde edilen sonuçların işitsel deneyimi ve genel gelişiminden etkilendiği düşünülmüştür. Olgu 2'de VRISD test sonuçlarında doğru yanıt alınamamıştır ve bunun sebebinin ek engelinin bulunması ile ilişkili olduğu düşünülmüştür. VRISD testinde cevap olarak motor bir davranış olan şartlandırılmış baş çevirme hareketi değerlendirildiği için bebeğin test esnasında uyaran değişikliği olduğunda şartlandırılmış baş çevirme hareketi dışındaki cevapları kabul edilmemiştir. Olgu 3'te; bebekten her iki uyaran çifti için de doğru cevap elde edilememesinin, bebeğin işitsel deneyiminin yetersiz olmasından kaynaklandığı düşünülmüştür.

Her üç olguda da /ba/-/da/ uyaran çiftinde doğru uyaran ayırt etme yanıtının alınamamasinın, uyaranları ayırt etmenin zorluğundan ve bebeğin testten sıkılmış olmasından kaynaklandığı gözlenmiştir. Uhler yaptığı çalışmada, VRISD test yöntemi ile/ba/-/da/ ve /a/-/i/ uyaranlarını kullanarak normal işitmeye sahip bebekleri değerlendirmiş ve en yüksek sunum düzeyinde bebeklerin \%29'unun /ba/-/da/ uyaran çifti ayrımında başarısız olduklarını ve en kolay ayırt edilebilen uyaran çiftinin /a/- /i/ olduğu rapor edilmiştir. Bu sebepten çalışmamızda /a//i/ ve /ba/- /da/ uyaran çiftlerini tercih ettik. Ünsüz fonemlerin ayırt edilmesine yönelik "başarısızlık" oranı, daha önceki çalışmalarda bildirilenlere benzerdir (Kristin Uhler, YoshinagaItano, Gabbard, Rothpletz, \& Jenkins, 2011). Literatürde; koklear implant kullanıcıları ve normal işitmeye sahip bebekler VRISD testi ile değerlendirilmiş ve koklear implant kullanıcısı bebekler ile normal işitmeye sahip bebeklerin konuşmayı algılama yeteneklerinin benzer olduğu ve $/ \mathrm{ba} /-/ \mathrm{da} /$ uyaran çiftinde düşük skor gözlendiği rapor edilmiştir (Akkaplan, Batuk, \& Sennaroglu, 2021).
VRISD testinin öğrenme aşamasında hedef sesin tekrar sıklığını arttırarak ve uyaran süresini uzatarak bebeklerin öğrenmelerini kolaylaştırmak amaçlanmıştır. İşitme cihazı kullanıcısı bebeklerde hedef sesin daha uzun süre pekiştireç ile birlikte sunulması gerekmektedir. Koklear implant kullanıcısı bebeklerde VRISD test yöntemi kullanılarak yapılan çalışmada, testte kullanılan hedef uyaran süresinin uzatılması önerilmiştir (Akkaplan et al., 2021).

Çalışmamızda test sonuçlarını etkileyen birçok faktör olduğu gözlemlenmiştir. Bebeğin kendini güvende hissetmesi için ebeveyne yakın pozisyonlanması, karnının tok ve uykusunu almış olması testin devamlılığ için oldukça önemlidir. Çalışmamızda VRISD testinde hiçbir bebek \%100 başarı kriterine ulaşamamıştır. Literatürde birçok çalışmada benzer sonuçlara yer verilmiştir. Nozza ve ark. yaptıkları çalışmada, ideal test ortamında (bebek keyifli, dikkat dağıtıcı veya pekiştireç ile çok fazla ilgilenmiyorken) ayırt etmesi daha kolay olan kontrastlarda bile bebeklerin $\% 100$ başarı kriterine ulaşamadığı vurgulamıştır. Ayrıca bir sinyal varlığını fark etme becerisinin, sinyal değişikliğini ayırt etme becerisinde daha az dikkat gerektirdiği ve bu yüzden bebek test süresi içinde iyi performans gösterse bile $\% 100$ başarı kriterine ulaşılamayacağ 1 belirtilmiştir (Nozza, 1987).

Bebeklerde dil edinimi, işitsel gelişim, konuşmayı algılama gelişimi hakkında erken dönemde geniş ölçüde bilgi sahibi olmamıza katkıda bulunur. Bebeklerin konuşma algılamasını değerlendiren bu objektif ölçümlerden elde edilen sonuçlar aynı zamanda habilitasyon çalışmalarını yönlendirmeye ve izlemeye yardımcı olur.

VRISD testi bebeklerde konuşmayı ayırt etme becerisinin objektif ölçümünde kullanılan etkin bir yöntem olması nedeniyle bebeklerde klinik uygulamalarda amplifikasyon ayarları ve işitsel eğitim programlarının planlanmasında yol gösterici olabilmektedir. Gelecek çalışmalarda, VRISD test tekniğinde uyaranların ve test parametrelerinin incelenmesi, uyaranlar arasındaki sürenin artırılmasının gerekliliğinin belirlenmesi ve işitme kaybı olan bebekleri test ederken ideal uyaranlar arası süre olup olmadığının değerlendirilmesi gereklidir.

Peer-review: Externally peer-reviewed.

Author Contributions: Concept- MB, SA; Design- GS, MB; Supervision-MB, GS; Data Collection and/or Processing- SA; Analysis and/or Interpretation- SA, MB; Literature Search- SA; Writing Manuscript- SA.

Conflict of Interest: No conflict of interest.

Financial Disclosure: None.

Hakem Değerlendirmesi: Dış Bağımsız.

Yazar Katkıları: Fikir- MB, SA; Tasarım- MB, GS; Denetleme- MB, GS; Veri Toplanması ve/veya İşlemesi- SA; Analiz ve/veya Yorum- SA, MB; Literatür Taraması- SA; Yazıyı Yazan- SA.

Çıkar Çatışması: Yoktur.

Finansal Destek: Finansal destek kullanılmamıştır. 


\section{KAYNAKLAR}

Akkaplan, S., Batuk, M. O., \& Sennaroglu, G. (2021). Auditory perception skills in children receiving simultaneous bilateral cochlear implants: early speechdiscrimination results. European Archives of Oto-Rhino-Laryngology. doi:10.1007/s00405-020-06579-3

Downs, M. P., \& Sterritt, G. M. (1967). A guide to newborn and infant hearing screening programs. Archives of Otolaryngology, 85(1), 15-22.

Eilers, R. E., Gavin, W., \& Wilson, W. R. (1979). Linguistic experience and phonemic perception in infancy: A crosslinguistic study. Child Development, 14-18.

Eimas, P. D., Siqueland, E. R., Jusczyk, P., \& Vigorito, J. (1971). Speech perception in infants. Science, 171(3968), 303-306.

Grieser, D., \& Kuhl, P. K. (1989). Categorization of speech by infants: Support for speech-sound prototypes. Developmental Psychology, 25(4), 577.

Kuhl, P. K. (1991). Human adults and human infants show a "perceptual magnet effect" for the prototypes of speech categories, monkeys do not. Perception \& psychophysics, 50(2), 93-107.

Lisker, L., \& Abramson, A. S. (1964). A cross-language study of voicing in initial stops: Acoustical measurements. Word, 20(3), 384-422.

Moeller, M. P. (2000). Early intervention and language development in children who are deaf and hard of hearing. Pediatrics, 106(3), E43. doi:10.1542/ peds.106.3.e43

Nozza, R. J. (1987). Infant speech-sound discrimination testing: Effects of stimulus intensity and procedural model on measures of performance. The Journal of the Acoustical Society of America, 81(6), 1928-1939.

Nozza, R. J. (2000). Thresholds are not enough: Understanding how infants process speech has a role in how we manage hearing loss. Paper presented at the A sound foundation through early amplification: Proceedings of an international conference. Stäfa, Switzerland: Phonak AG.

Nozza, R. J., \& Wilson, W. R. (1984). Masked and unmasked pure-tone thresholds of infants and adults: Development of auditory frequency selectivity and sensitivity. Journal of Speech, Language, and Hearing Research, 27(4), 613622 .
Sloutsky, V. M., \& Napolitano, A. C. (2003). Is a picture worth a thousand words? Preference for auditory modality in young children. Child Dev, 74(3), 822-833. doi:10.1111/1467-8624.00570

Strange, W., \& Jenkins, J. J. (1978). Role of linguistic experience in the perception of speech. In Perception and experience (pp. 125-169): Springer.

Tomblin, J. B., Oleson, J. J., Ambrose, S. E., Walker, E., \& Moeller, M. P. (2014). The influence of hearing aids on the speech and language development of children with hearing loss. JAMA Otolaryngol Head Neck Surg, 140(5), 403-409. doi:10.1001/jamaoto.2014.267

Uhler, K., \& Gifford, R. H. (2014). Current trends in pediatric cochlear implant candidate selection and postoperative follow-up. Am J Audiol, 23(3), 309-325. doi:10.1044/2014_aja-13-0067

Uhler, K., Yoshinaga-Itano, C., Gabbard, S. A., Rothpletz, A. M., \& Jenkins, H. (2011). Longitudinal infant speech perception in young cochlear implant users. Journal of the American Academy of Audiology, 22(3), 129-142.

Uhler, K. M., Baca, R., Dudas, E., \& Fredrickson, T. (2015). Refining stimulus parameters in assessing infant speech perception using visual reinforcement infant speech discrimination: Sensation level. Journal of the American Academy of Audiology, 26(10), 807-814.

Werker, J. F., Polka, L., \& Pegg, J. E. (1997). The conditioned head turn procedure as a method for testing infant speech perception. Early Development and Parenting, 6(3-4), 171-178. doi:https://doi.org/10.1002/(SICI)10990917(199709/12)6:3/4<171::AID-EDP156>3.0.CO;2-H

Werker, J. F., \& Tees, R. C. (1984). Cross-language speech perception: Evidence for perceptual reorganization during the first year of life. Infant behavior and development, 7(1), 49-63.

Zupan, B., \& Sussman, J. E. (2009). Auditory preferences of young children with and without hearing loss for meaningful auditory-visual compound stimuli. J Commun Disord, 42(6), 381-396. doi:10.1016/j.jcomdis.2009.04.002 